\title{
Effect of winglet vortex generators configuration on thermal performance of a heated rectangular channel
}

\author{
Khudheyer S. Mushatet \\ Mech. Eng. Dept. Mech. Eng. Dept. \\ College of Engineering \\ Thi-Qar University \\ E-mail:khudheyersalim@gmail.com
}

\author{
Iltifat lazim edan \\ Mech. Eng. Dept. Mech. Eng. Dept. \\ College of Engineering \\ Thi-Qar University \\ E-mail:el_la49@yahoo.com
}

\begin{abstract}
In present paper, a three dimensional turbulent flow and heat transfer inside a rectangular channel equipped with array of winglet vortex generators has been investigated experimentally and numerically. Three pairs array of winglet vortex generators of different geometrical configuration as rectangular, triangular, semi circle and parabolic are considered. The array of winglet vortex generators is formed and distributed on the bottom hot surface with a facility for changing the angle of attack from $\left(0^{\circ}\right.$ to $\left.60^{\circ}\right)$. ANSYS Fluent Code (15.0) based on a finite volume method is used to get the numerical results while a $\mathrm{k}-\omega$ turbulence model is used to model the turbulent . The Reynolds number range is from 10000 to 50,000 under a constant heat flux boundary condition. The spin wise between the vortex generators are set to $1 \mathrm{~cm}$ and $1.5 \mathrm{~cm}$ while the stream wise between the vortex are $9 \mathrm{~cm}, 12 \mathrm{~cm}$ and $18 \mathrm{~cm}$ respectively. The results indicated that the rectangular winglet vortex generators array indicated the optimum thermal performance with considerable penalty of the pressure drop while the parabolic vortex generator stated the minimum performance among the considered vortex generators shapes. The overall efficiency for rectangular, triangular, semi circle and parabolic winglet vortex generators is enhanced by (166\%), $(130 \%),(165 \%)$ and $(121 \%)$ respectively as compared with plane channel.
\end{abstract}

Keywords: Vortex generators, turbulent flow, heat transfer enhancement .

\section{Introduction}

During latest years, serious attempts have been made to apply different active and passive methods for heat transfer enhancement in compact heat exchangers for the automotive industry, airconditioning and refrigerant applications, internal cooling for gas turbine blades, electrical circuits in electronic chipsets, etc. Achieving higher heat transfer rates through various augmentation techniques can result in substantial energy savings, more compact and less expensive apparatus with higher thermal efficiency. The vortex generators are considered as a kind of passive heat-transfer enhancing devices. Vortex generators have been generally investigated to improve the convective heat transfer coefficient. The basic principle of vortex generator is to induce secondary flow, particularly longitudinal vortices longitudinal vortex generator, which could disturb or cut off the thermal boundary layer developed along the wall and remove the heat from the wall to the core of the flow by means of large-scale turbulence [1]. Experimental research by Feibig et al. [2] showed the average heat transfer in laminar channel-flow was enhanced by more than $50 \%$ and the corresponding increase of drag coefficient was up to $45 \%$ by delta and rectangular wings and winglets. Jain et al. [3] proposed a common flow-up configuration delta winglet that causes significant separation delay, reduced form drag and removes the zones of poor heat transfer. Gentry and Jacobi [4,5] experimentally studied heat transfer enhancement characteristics of 
delta wing vortex generators in a flat-plate channel flow. Results showed that the average heat could be enhanced by $50-60 \%$ at low Reynolds number in comparison with the original configuration. Liou et al. [6] performed comparative studies in terms of heat transfer augmentation and friction loss on 12 different configurations of longitudinal vortex generators. It was found that direction and strength of the secondary flow are the more important fluid dynamic factors affecting heat transfer, followed importance by fluid velocity, and then turbulent kinetic energy. Du et al. [7] numerically studied the flow structure and heat transfer enhancement of LVGs applied in direct air e cooled condenser using RNG k- $\varepsilon$ model and found that the delta winglet pair with attack angle of $25^{\circ}$ could reach the optimum thermal and flow performances. Habchi et al. [8] numerically investigated the performance of trapezoidal wing with excavation at the bottom. The results showed the convective heat transfer between the vortex generator and the surrounding fluid is decreased. Therefore, the size of the cavity should be optimized to maximize the effect of heat transfer enhancement and flow resistance reduction. $\mathrm{Wu}$ and Tao [9] also did numerical study on thermal hydraulic performance of rectangular winglets with punched holes at the channel wall and found that the case with punched holes had slightly higher average $\mathrm{Nu}$ number (about $1.1 \%$ ) and slightly lower average friction factor (about 1.2\%) compared with the case without punched holes. Zhou and Ye [10] experimentally investigated the heat transfer performance of a new vortex generator called curved trapezoidal winglet and compared rectangular winglet. Wang et al. [11] found that longitudinal vortex generator configurations play an important role in heat transfer enhancement that can greatly improve heat transfer rates by $10-45 \%$. Furthermore, heat transfer performance of channels with LVGs on both sides is better than those just on one. Min et al. [12] developed a modified rectangular longitudinal
Effect of winglet vortex generators configuration on thermal performance of a heated rectangular channel vortex generator (LVG) obtained by cutting off the four corners of a rectangular wing. Their experimental results of this longitudinal mounted in rectangular channel suggested that the modified rectangular wing pairs of the modified rectangular wing pairs have better flow and heat transfer characteristics than those of rectangular wing pair. Zhang et al. [13] examined numerically the thermal enhancement and flow resistance characteristics in a rectangular channel with novel structures of double delta winglets and double delta winglet with holes. The double delta winglets with larger angle could make more effective heat transfer enhancement. Caliskan [14] studied the heat transfer enhancement of punched LVGs using the infrared thermal image technique. He reported $23-55 \%$ increase in heat transfer performance and correlations for $\mathrm{Nu}$ were developed for corresponding LVGs. Leu et al. [15] investigated numerically and experimentally of the rectangular winglet pairs for three in-line tube rows. The angles of attack, the $45^{\circ}$ arrangement provided the best overall performance and achieved up to $25 \%$

In this work ,a numerical and experimental study for three -dimensional turbulent flow and heat transfer in a channel with common flow up arrangement of winglet vortex generator is performed. Three pairs array of winglet vortex generators of different geometrical configuration as rectangular, triangular, semi-circle and parabolic are used. In addition a parabolic winglet type is tested as new suggested configuration under low and high Reynolds number rang $\left(\operatorname{Re}=10^{3}\right.$ to $\left.5 \times 10^{3}\right)$. Different values of stream wise distance which dimensionlized with channel height as $X_{r}=1.5,2$ and 3 are studied.

\section{Problem Description}

The geometry consists of three dimensional rectangular channel with winglet vortex generators array as shown in Fig. (1). Four types of winglet vortex generators as Triangular, Rectangular, Semi circle and parabolic are tested. Different angles of 
$\operatorname{attack}\left(\beta=0^{\circ}, 30^{\circ}, 45^{\circ}\right.$ and $\left.60^{\circ}\right)$ for vortex generators are studied.

The channel of length $(\mathrm{L}=1.08 \mathrm{~m})$, height $(\mathrm{H}$ $=0.06 \mathrm{~m})$ and width $(\mathrm{W}=0.18 \mathrm{~m})$. Different sizes of vortex generators are considered while the ratio of area of the vortex generator with respect to the area of the channel inlet $\left(A_{r}\right)$ is kept constant. Three values of area ratio $\left(\mathrm{A}_{\mathrm{r}}\right)$ as $0.0740,0.0370$, and 0.0231 are considered. Different values of stream
Effect of winglet vortex generators configuration on thermal performance of a heated rectangular channel wise distance which dimensionlized with channel height as $\mathrm{X}_{\mathrm{r}}=1.5,2$ and 3 are tested. In addition,the spine wise dimensionless distance as $\mathrm{Zr}=1,1.5$ is included. The distance from the channel inlet to the first pair of vortex generators is kept constant at $(0.18) \mathrm{cm}$ for the studied geometrical parameters.

$\mathrm{Z}_{\mathrm{r}}=\frac{s}{H}, \mathrm{X}_{\mathrm{r}}=\frac{p}{H}$
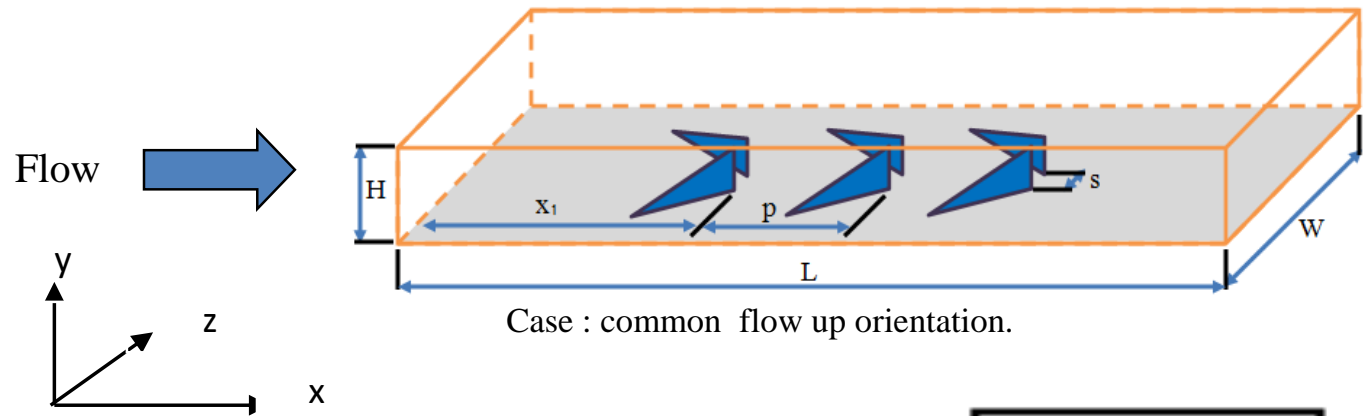

Case : common flow up orientation.

Fig.(1) Schematic diagram of the physical p1

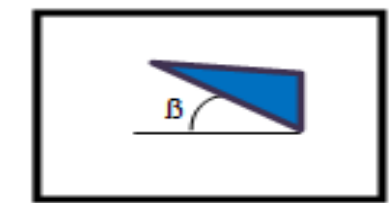

\section{Mathematical Formulation and Numerical}

\section{Methods}

To analyze the thermal and flow characteristics of this model, the following assumptions are made:

1. Incompressible flow.

2. The fluid is stagnant and Newtonian air.

3.Non slip flow.

4. The dissipation of heat is assumed to be neglected.

5.Steady state.

$\frac{\partial \mathrm{u}}{\partial \mathrm{x}}+\frac{\partial \mathrm{v}}{\partial \mathrm{y}}+\frac{\partial \mathrm{w}}{\partial \mathrm{z}}=0$

b- Momentum equation

X-Direction
6 . The gravity effect is neglected .

7. Three dimensional analysis.

8. Constant physical properties for the fluid .

9.The enfluence of thickness of vortex generators is neglected.

The effect of turbulence is modeled by using a $\boldsymbol{k}-\boldsymbol{\omega}$ model. The governing equation for the continuity, momentum and energy based on the above assumptions are as follows.

a-Continuity equation 


$$
\begin{aligned}
\left(\frac{\partial \mathrm{u}^{2}}{\partial \mathrm{x}}+\frac{\partial \mathrm{uv}}{\partial \mathrm{y}}+\frac{\partial \mathrm{uw}}{\partial \mathrm{z}}\right)=- & \frac{1}{\rho} \frac{\partial \mathrm{P}}{\partial \mathrm{x}}+\frac{\partial}{\partial \mathrm{x}}\left(\mathrm{v} \frac{\partial \mathrm{u}}{\partial \mathrm{x}}\right)+\frac{\partial}{\partial \mathrm{y}}\left(\mathrm{v} \frac{\partial \mathrm{u}}{\partial \mathrm{y}}\right)+\frac{\partial}{\partial \mathrm{z}}\left(\mathrm{v} \frac{\partial \mathrm{u}}{\partial \mathrm{z}}\right) \\
& +\frac{\partial}{\partial \mathrm{x}}\left(-\overline{\mathrm{u}^{2}}\right)+\frac{\partial}{\partial \mathrm{y}}(-\overline{\mathrm{u}})+\frac{\partial}{\partial \mathrm{z}}(-\overline{\mathrm{u}} \bar{w})
\end{aligned}
$$

Y-Direction

$$
\begin{aligned}
\left(\frac{\partial \mathrm{vu}}{\partial \mathrm{x}}+\frac{\partial \mathrm{v} \mathrm{V}^{2}}{\partial \mathrm{y}}+\frac{\partial \mathrm{vw}}{\partial \mathrm{z}}\right)=- & \frac{1}{\rho} \frac{\partial \mathrm{P}}{\partial \mathrm{y}}+\frac{\partial}{\partial \mathrm{x}}\left(\mathrm{v} \frac{\partial \mathrm{v}}{\partial \mathrm{x}}\right)+\frac{\partial}{\partial \mathrm{y}}\left(\mathrm{v} \frac{\partial \mathrm{v}}{\partial \mathrm{y}}\right)+\frac{\partial}{\partial \mathrm{z}}\left(\mathrm{v} \frac{\partial \mathrm{v}}{\partial \mathrm{z}}\right) \\
+ & \frac{\partial}{\partial \mathrm{x}}(-\overline{\mathrm{u}} \bar{v})+\frac{\partial}{\partial \mathrm{y}}\left(-\overline{\hat{\mathrm{v}}^{2}}\right)+\frac{\partial}{\partial \mathrm{z}}(-\overline{\mathrm{v} ́})
\end{aligned}
$$

Z-direction

$$
\begin{aligned}
\left(\frac{\partial \mathrm{wu}}{\partial \mathrm{x}}+\frac{\partial \mathrm{wv}}{\partial \mathrm{y}}+\frac{\partial \mathrm{w}^{2}}{\partial \mathrm{z}}\right) & =-\frac{1}{\rho} \frac{\partial \mathrm{P}}{\partial \mathrm{z}}+\frac{\partial}{\partial \mathrm{x}}\left(\mathrm{v} \frac{\partial \mathrm{w}}{\partial \mathrm{x}}\right)+\frac{\partial}{\partial \mathrm{y}}\left(\mathrm{v} \frac{\partial \mathrm{w}}{\partial \mathrm{y}}\right)+\frac{\partial}{\partial \mathrm{z}}\left(\mathrm{v} \frac{\partial \mathrm{w}}{\partial \mathrm{z}}\right) \\
& +\frac{\partial}{\partial \mathrm{x}}(-\overline{\mathrm{u} w})+\frac{\partial}{\partial \mathrm{y}}(-\overline{\mathrm{v} w})+\frac{\partial}{\partial \mathrm{z}}\left(-\overline{\dot{w}^{2}}\right)
\end{aligned}
$$

Where U,V,W,T is the fluctuation from the mean There ,Equation (4) becomes:

$$
\frac{\partial \mathrm{UT}}{\partial \mathrm{x}}+\frac{\partial \mathrm{VT}}{\partial \mathrm{y}}+\frac{\partial \mathrm{WT}}{\partial \mathrm{z}}=\frac{\partial}{\partial \mathrm{x}}
$$

$$
\begin{aligned}
& \left(\Gamma \frac{\partial \mathrm{T}}{\partial \mathrm{x}}\right)+\frac{\partial}{\partial \mathrm{y}}\left(\Gamma \frac{\partial \mathrm{T}}{\partial \mathrm{y}}\right)+\frac{\partial}{\partial \mathrm{z}}\left(\Gamma \frac{\partial \mathrm{T}}{\partial \mathrm{z}}\right)+ \\
& \frac{\partial}{\partial \mathrm{x}}\left(-\overline{\mathrm{u}^{\prime} \mathrm{T}^{\prime}}\right)+\frac{\partial}{\partial \mathrm{y}}\left(-\overline{\mathrm{v}^{\prime} \mathrm{T}^{\prime}}\right)+ \\
& \frac{\partial}{\partial \mathrm{z}}\left(-\overline{\mathrm{w}^{\prime} \mathrm{T}^{\prime}}\right)
\end{aligned}
$$

\section{3-1The Standard (k- $\omega)($ SST) Model}

The shear-stress transport (SST) k- $\omega$ model developed by Menter [24] is used. This turbulence model solves two additional partial differential equations; that is used as a closure for the Reynolds-averaged Navier-Stokes equations. The standard $(k-\omega)(\mathrm{SST})$ model is an empirical model based on model transport equations for the turbulence kinetic energy $(k)$ and the specific dissipation rate $(\omega)$. Also, the shear stress transport (SST) combines the use of $k-\omega$ formulation in the inner parts of the boundary layer and the switching to a $\mathrm{k}-\varepsilon$ behavior in the free-stream thus avoiding the $\mathrm{k}-\mathrm{u}$ sensitivity to the inlet free-stream turbulence properties. In addition, this model is characterized by its good behavior in adverse pressure gradients.

The SST k- $\omega$ model transport equations are:

For turbulent kinetic energy $(\boldsymbol{k})$ :

$$
\left(\frac{\partial}{\partial \mathrm{x}}(\boldsymbol{k} \mathrm{U})+\frac{\partial}{\partial \mathrm{y}}(\boldsymbol{k} \mathrm{V})+\frac{\partial}{\partial \mathrm{z}}(\boldsymbol{k} \mathrm{W})\right)=\frac{\partial}{\partial \mathrm{x}}\left(\frac{v_{\mathrm{t}}}{\sigma_{\boldsymbol{k}}} \frac{\partial \boldsymbol{k}}{\partial \mathrm{x}}\right)+\frac{\partial}{\partial \mathrm{y}}\left(\frac{v_{\mathrm{t}}}{\sigma_{\boldsymbol{k}}} \frac{\partial \boldsymbol{k}}{\partial \mathrm{y}}\right)+\frac{\partial}{\partial \mathrm{z}}\left(\frac{v_{\mathrm{t}}}{\sigma_{k}} \frac{\partial \boldsymbol{k}}{\partial \mathrm{z}}\right)+\mathrm{G}_{\mathrm{k}}-\mathrm{Y}_{\mathrm{k}}+\mathrm{S}_{\mathrm{k}}
$$

In these equations $\left(\mathrm{G}_{\mathrm{k}}\right)$ represents the generation of turbulence kinetic energy due to mean velocity gradients. $\mathrm{Y}_{\mathrm{k}}$ represents the dissipation of $(\mathrm{k})$ due to turbulence. $\mathrm{S}_{\mathrm{k}}$ is user-defined source terms.

Where $\left(G_{k}\right)$ is referred to the generation term: 


$$
\begin{aligned}
\mathrm{G}_{\mathrm{k}}=\boldsymbol{v}_{\mathrm{t}}\left[2\left(\frac{\partial \mathrm{U}}{\partial \mathrm{x}}\right)^{2}\right. & +2\left(\frac{\partial \mathrm{V}}{\partial \mathrm{y}}\right)^{2}+2\left(\frac{\partial \mathrm{W}}{\partial \mathrm{z}}\right)^{2}+\left(\frac{\partial \mathrm{U}}{\partial \mathrm{y}}+\frac{\partial \mathrm{V}}{\partial \mathrm{x}}\right)^{2}+\left(\frac{\partial \mathrm{V}}{\partial \mathrm{z}}+\frac{\partial \mathrm{W}}{\partial \mathrm{y}}\right)^{2} \\
& \left.+\left(\frac{\partial \mathrm{U}}{\partial \mathrm{z}}+\frac{\partial \mathrm{W}}{\partial \mathrm{x}}\right)^{2}\right]
\end{aligned}
$$

Where $Y_{k}=\rho ß \omega^{2}$

For energy dissipation rate $(\boldsymbol{\omega})$ :

$$
\begin{aligned}
& \left(\frac{\partial}{\partial \mathrm{x}}(\omega \mathrm{U})+\frac{\partial}{\partial \mathrm{y}}(\omega \mathrm{V})+\frac{\partial}{\partial \mathrm{z}}(\omega \mathrm{W})\right)=\frac{\partial}{\partial \mathrm{x}}\left(\frac{v_{\mathrm{t}}}{\sigma_{\omega}} \frac{\partial \omega}{\partial \mathrm{x}}\right)+\frac{\partial}{\partial \mathrm{y}}\left(\frac{v_{\mathrm{t}}}{\sigma_{\omega}} \frac{\partial \omega}{\partial \mathrm{y}}\right) \\
& +\frac{\partial}{\partial \mathrm{z}}\left(\frac{v_{\mathrm{t}}}{\sigma_{\omega}} \frac{\partial \omega}{\partial \mathrm{z}}\right)+\alpha_{1 \omega} \frac{\omega}{\mathrm{k}} \mathrm{G}-\alpha_{2 \omega} \frac{\omega^{2}}{\mathrm{k}}
\end{aligned}
$$

\section{3-2 Boundary Conditions}

Boundary conditions are specified for each zone of the computational domain as follow:

\section{At inlet:}

Uniform inlet velocity , $\mathrm{U}=\mathrm{U}_{\text {in }}$.

The flow is isothermal $\left(T=T_{i n}=300 K\right)$.

\section{At walls :}

1- On the channel walls and vortex generators, the velocity taken to be zero (no slip), $\mathrm{u}=\mathrm{v}=\mathrm{w}=0$.

2- A constant heat flux $\left(q=1000 \mathrm{~W} / \mathrm{m}^{2}\right)$ is imposed on the bottom surface.

3- $\frac{\partial p}{\partial n}=0$, where $\mathrm{n}$ is a normal unit vector .

$\operatorname{Re}=\frac{\rho U_{\text {in }} D_{H}}{\mu}$

$\mathrm{D}_{\mathrm{h}}=\frac{4 A_{C}}{P}=\frac{2 H W}{(H+W)}$

Where $\mathrm{D}_{\mathrm{h}}$ is the hydraulic diameter, $\mathrm{A}_{\mathrm{c}}$ is the channel cross section area and $\mathrm{P}$ is the wetted perimeter.

The friction coefficient at the channel bottom wall is as :

$\mathrm{C}_{\mathrm{f}}=\frac{\tau_{w}}{\frac{1}{2} \rho U_{\text {in }}^{2}}$

Where $\tau_{\mathrm{w}}$ is the wall shear stress and defined as :

1-A zero gage pressure is specified at the outlet domain.

2- Smooth exit for dependent variables $\left(\frac{\partial U}{\partial x}=\frac{\partial V}{\partial x}=\right.$ $\left.\frac{\partial W}{\partial x}=0\right)$ are assumed

\section{3-3 Hydrodynamic and thermal Parameters}

In this section, signification parameters are defined as below: 
$\tau_{\mathrm{w}}=\mu \sqrt{\left(\frac{\partial u}{\partial y}\right)^{2}+\left(\frac{\partial w}{\partial y}\right)^{2}}$

The bulk temperature is described as:

$\mathrm{Tb}=\frac{\int_{0}^{\mathrm{L}} \int_{0}^{\mathrm{H}} \int_{0}^{W} \rho C p_{p} u T d x d y d z}{\int_{0}^{\mathrm{L}} \int_{0}^{\mathrm{H}} \int_{0}^{W} \rho C p^{u} d x d y d z}$

The wall temperature is described as:

$\mathrm{T}_{\mathrm{w}}=\frac{1}{A_{(x, z)}} \int_{0}^{l} \int_{0}^{w} T_{w} d z d x$

The pressure drop is described as: $\Delta P=\int_{0}^{\mathrm{L}} \int_{0}^{\mathrm{W}} \Delta P d z d x$

The nussult number on the bottom heated surface is defined as:

$\mathrm{Nu}=\frac{1}{A_{(x, z)}} \int_{0}^{\mathrm{L}} \int_{0}^{\mathrm{W}} \mathrm{Nudzdx}$

\section{3-4 Grid independency}

For modeling the fluid flow problem by using the computational fluid dynamics, it is necessary to break the geometry into cells that include a mesh. It is important to have a good fine mesh which must have a good distribution cells in order to have an accurate solution, for this reason, a grid 
Effect of winglet vortex generators configuration on thermal performance of a heated rectangular channel

\begin{tabular}{|c|c|c|c|c|c|}
\hline Case & Grid & $\mathbf{N u}$ & $\mathbf{N u _ { \text { deviation } }}$ & $f$ & $f_{\text {diviation }}$ \\
\hline \multirow{3}{*}{$\begin{array}{l}\text { Plane channel } \\
\text { at } R e=10000\end{array}$} & 540000 & 34.757 & 0.051 & 0.008199 & 0.057 \\
\hline & 746496 & 36.66 & 0.00117 & 0.0087 & 0.009 \\
\hline & 933120 & 36.703 & & 0.00878 & \\
\hline \multirow{3}{*}{ T.V.G at $\beta=45$} & 1244398 & 52.275 & 0.001 & 0.017 & 0.15 \\
\hline & 1676622 & 52.2217 & 0.00015 & 0.0222 & 0.0044 \\
\hline & 2543513 & 52.2206 & & 0.0223 & \\
\hline \multirow{3}{*}{ T.V.G at $B=30$} & 1244398 & 43.2 & 0.03 & 0.010747 & 0.129 \\
\hline & 1676622 & 41.9 & 0.004 & 0.01236 & 0.0016 \\
\hline & 2543513 & 41.88 & & 0.01234 & \\
\hline \multirow{3}{*}{ R.V.G at $\beta=45$} & 1239872 & 55.7 & 0.02 & 0.011 & 0.15 \\
\hline & 1654880 & 54.24 & 0.0019 & 0.013 & 0.029 \\
\hline & 2466997 & 54.134 & & 0.0131 & \\
\hline \multirow{3}{*}{ S.V.G at $B=30$} & 1255860 & 46.8 & 0.031 & 0.0176 & 0.048 \\
\hline & 1697888 & 45.34 & 0.007 & 0.0185 & 0.00215 \\
\hline & 2498997 & 45.02 & & 0.01854 & \\
\hline \multirow{3}{*}{ P.V.G at $B=30$} & 1249924 & 45.5 & 0.023 & 0.0131 & 0.09 \\
\hline & 1678168 & 44.43 & 0.0092 & 0.0144 & 0.0013 \\
\hline & 2179983 & 44.02 & & 0.01442 & \\
\hline \multirow{3}{*}{ R.V.G at $\beta=30$} & 1259872 & 51.2 & 0.03 & 0.0147 & 0.0156 \\
\hline & 1697836 & 49.66 & 0.00322 & 0.0124 & 0.0024 \\
\hline & 2466997 & 49.5 & & 0.01243 & \\
\hline \multirow{3}{*}{ S.V.G at $B=45$} & 1244866 & 52.4 & 0.02 & 0.0125 & 0.067 \\
\hline & 1688743 & 53.87 & 0.00259 & 0.0134 & 0.00149 \\
\hline & 2498985 & 54.01 & & 0.01342 & \\
\hline \multirow{3}{*}{ P.V.G at $B=45$} & 1249844 & 50.3 & 0.0137 & 0.018 & 0.057 \\
\hline & 1678236 & 51 & 0.0039 & 0.0191 & 0.00526 \\
\hline & 2179889 & 51.2 & & 0.019 & \\
\hline
\end{tabular}

\section{Experimental Work}

The experimental test rig photographic in Fig.2 and schematic diagram in Fig.3 had had been used in this research. This system consists of the rectangular channel which fabricated from galvanize steel material. The channel has a length $(\mathrm{L}=108 \mathrm{~cm})$,

A heater of (3000)W is imposed to the bottom channel surface to generate a constant heat height $(\mathrm{H}=6 \mathrm{~cm})$ and width $(\mathrm{w}=18 \mathrm{~cm})$ as shown in Fig.(3).It consists of four walls, the two side walls are made of plexi glass to see clearly the vortex generators and consequently ensuring that they are in their specified positions. The top and bottom walls are fabricated from galvanized steel. 
flux $\left(q=1000 \mathrm{~W} / \mathrm{m}^{2}\right)$. A glass wool insulation is used

to insulate the bottom hot surface in order to prevent

the heat discination to outside channel

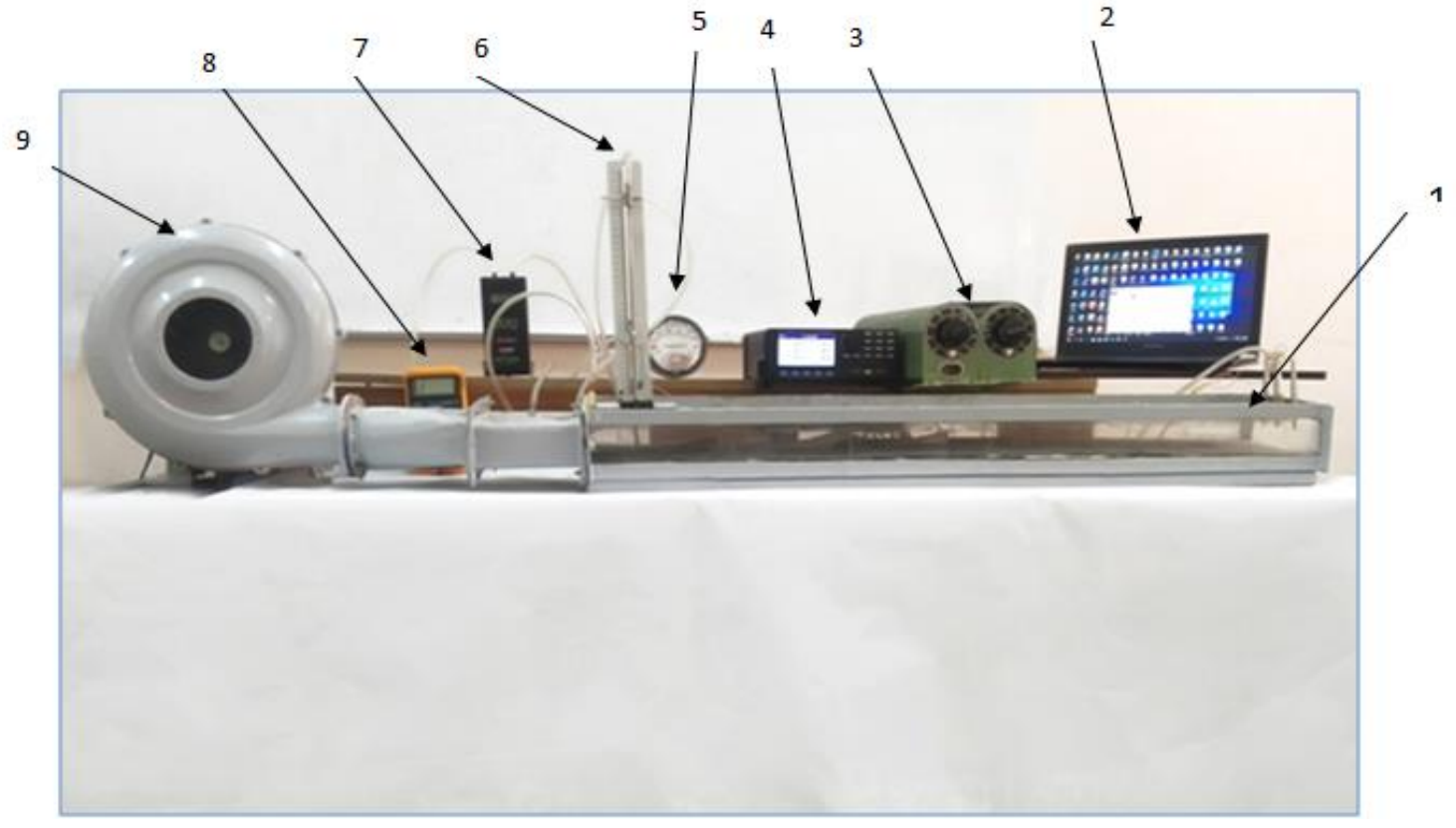

Figure (2) The photographic diagram

Table (2) shows the experimental parts of the test rig.

\begin{tabular}{|c|c|c|c|}
\hline 1 & Rectangular channel & 6 & Pitot tube \\
\hline 2 & Computer & 7 & Digital manometer \\
\hline 3 & Variac & 8 & Voltmeter \\
\hline 4 & Data logger & & Blower \\
\hline 5 & Magrfhelic different pressure gauge & 9 & \\
\hline
\end{tabular}




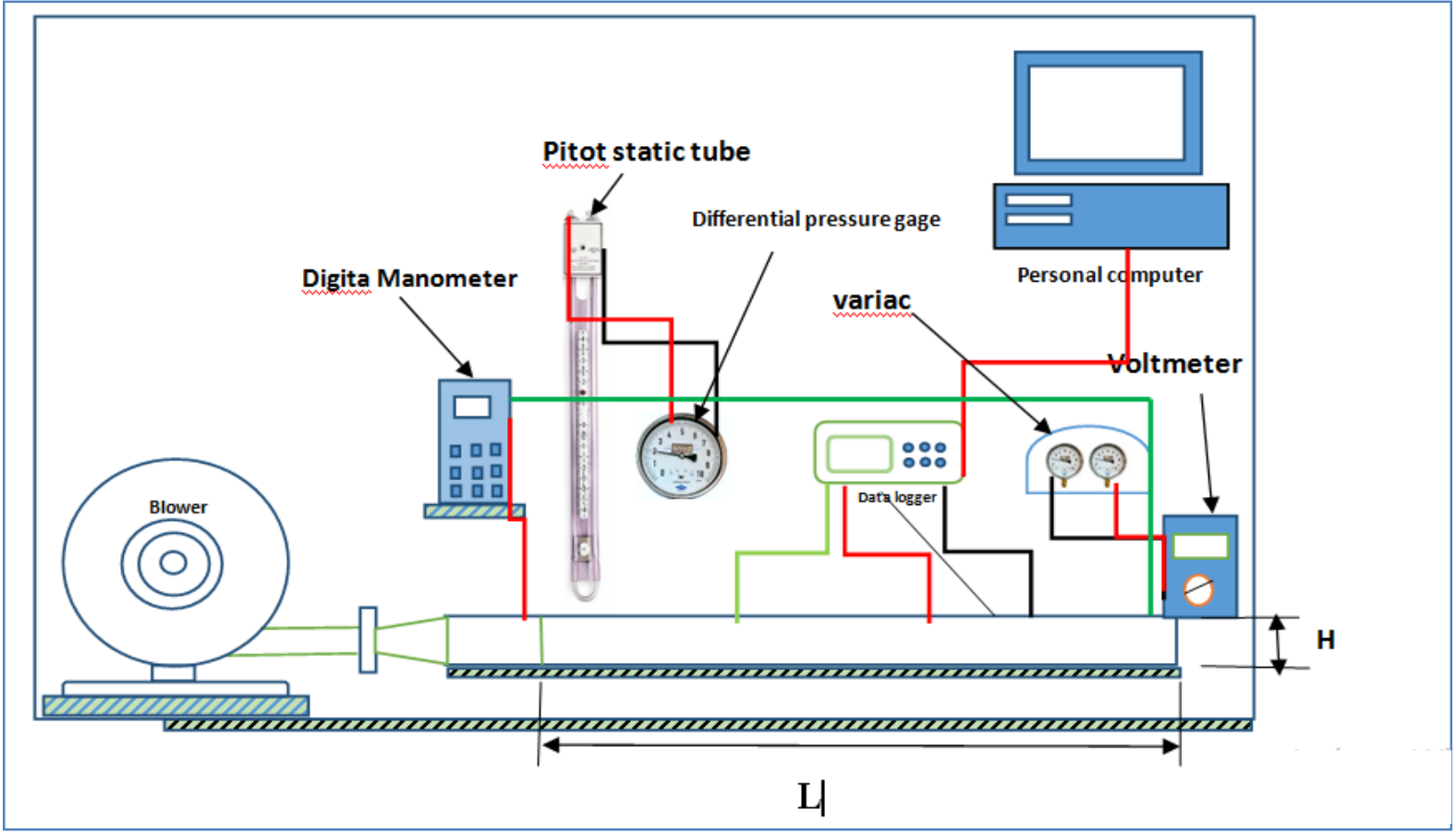

Figure(3) schematic diagram of the test rig.

\section{Results and discussion}

\subsection{Validation with published results}

A model validation must be performed to ensure that the present approach is reliable and

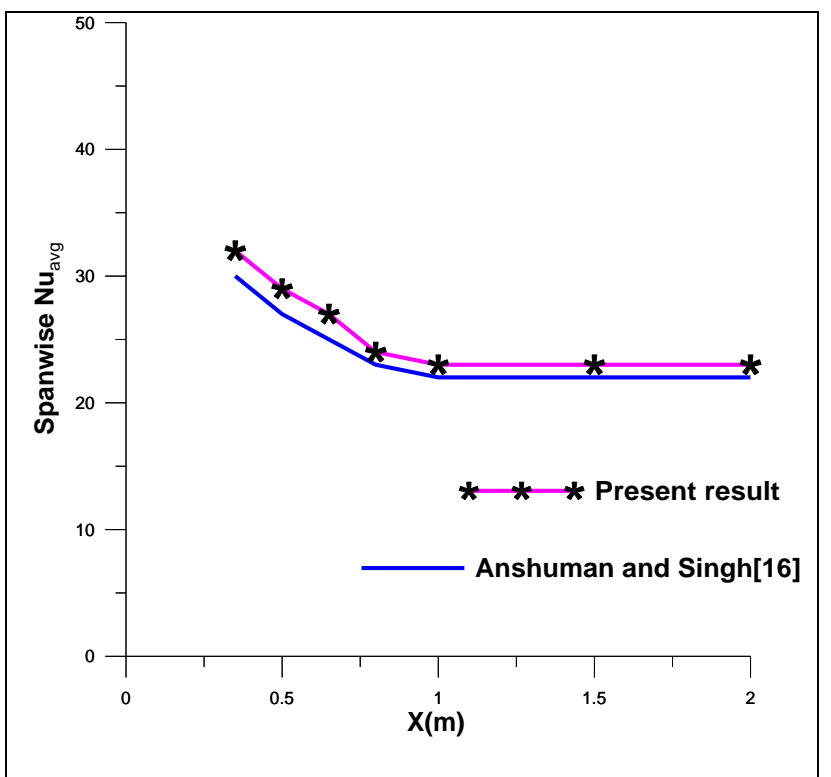

a. $\boldsymbol{B = 3 0 ^ { \circ }}$ applicable. This validation is done by comparing the results of the present model with results of Anshuman and Singh [16]as shown in Fig.(4). Acceptable agreement is obtained where the deviation does not exceeds $2 \%$ for $\mathrm{Re}=10000$.

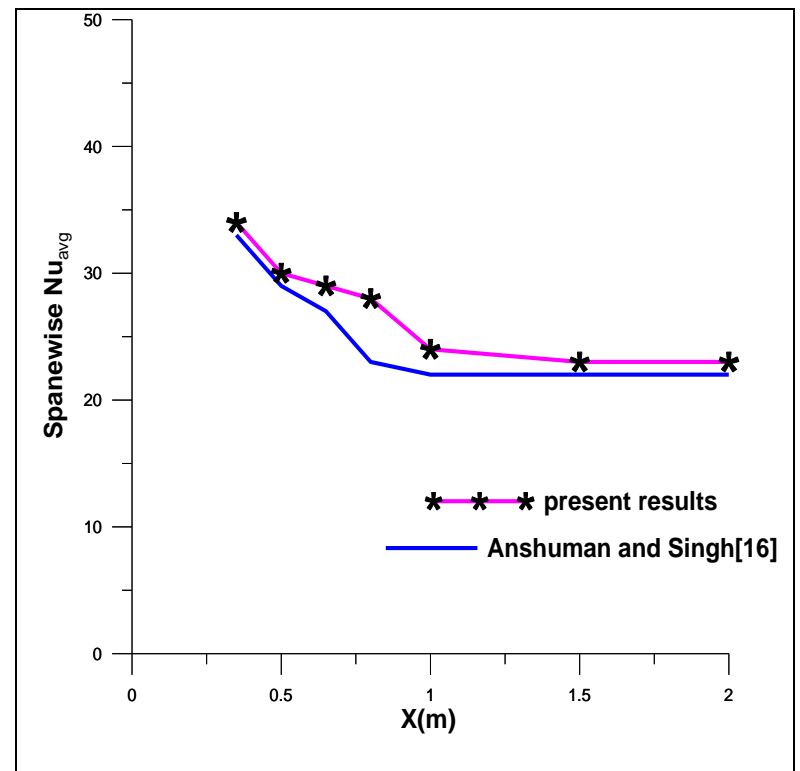

b. $\beta=45^{\circ}$ 


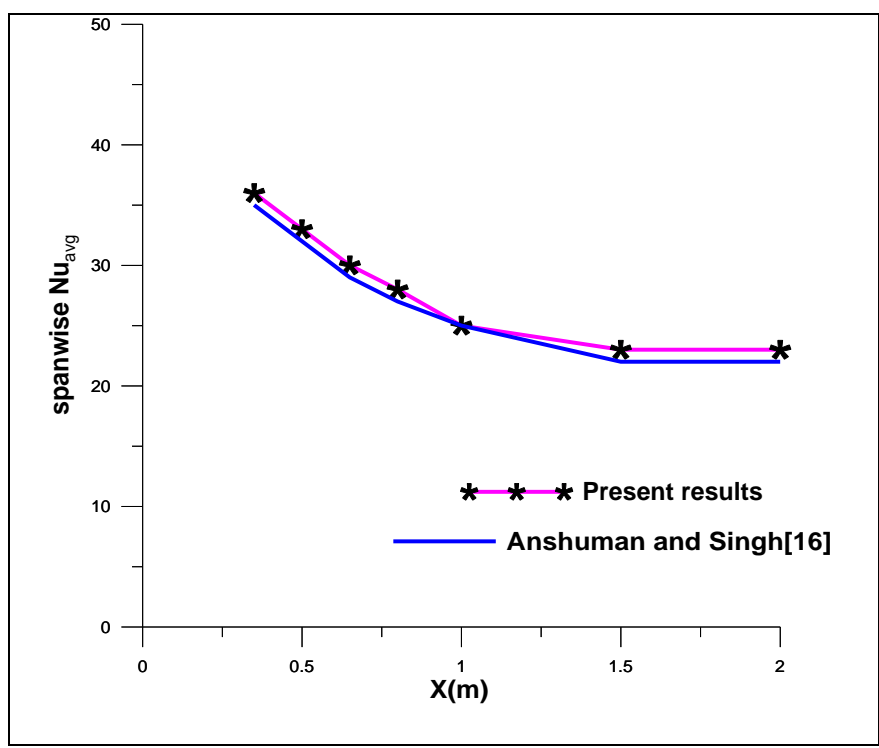

c. $\beta=60^{\circ}$

Fig(4) Comparison of the present result with the published result of the anshuman and singh [16]

Fig. (5 a, b, c) shows the variation of average Nusselt number with Reynolds number for different shapes of vortex generators for $\beta=45^{\circ}$ and $X_{r}=1.5$. Generally, it can be noted that the Nusselt number increases with the increasing Reynolds number because of the increasing the velocity which increases the heat transfer coefficient. It can be seen that, the rectangular vortex generators (R.V.G) provides a higher average Nusselt number than the semi-circle vortex generators (S.V.G), triangular vortex generators (T.V.G) and parabolic vortex

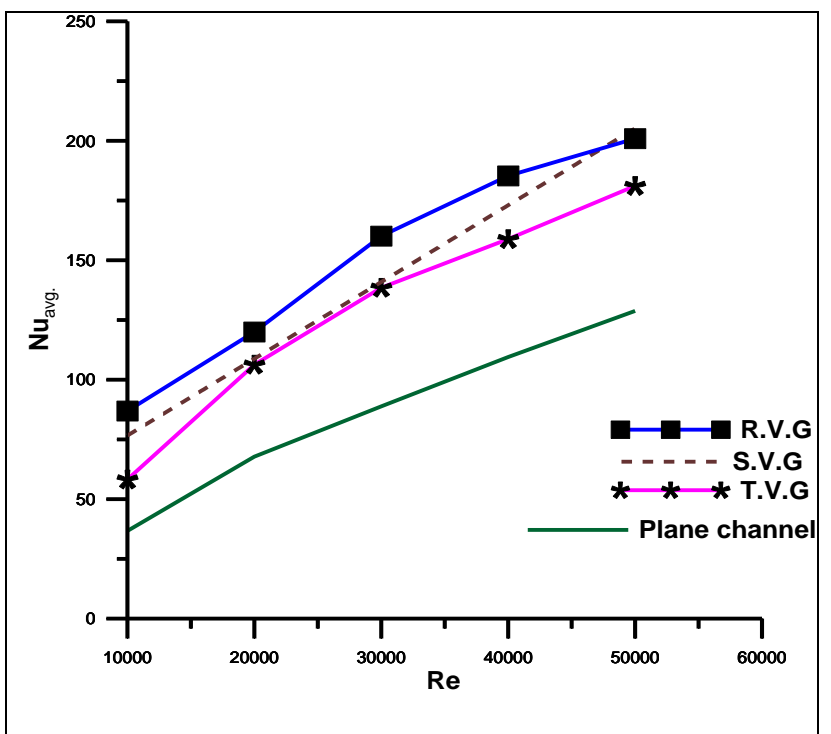

a. $\quad \mathrm{Ar}_{\mathrm{r}}=\mathbf{0 . 0 7 4 0}$ generators (P.V.G) for all considered Reynolds number values. This behavior due to the sudden expansion after the vortex generator. where of the RVG has the sharpest expansion with respect to the other shapes, which they have a gradual expansion. The sharpest expansion inducing the strongest longitudinal vortices and the higher flow obstruction, This configuration creates a stronger reverse flow as compared with those of other shapes, leading to better mixing between the core and the wall flows.

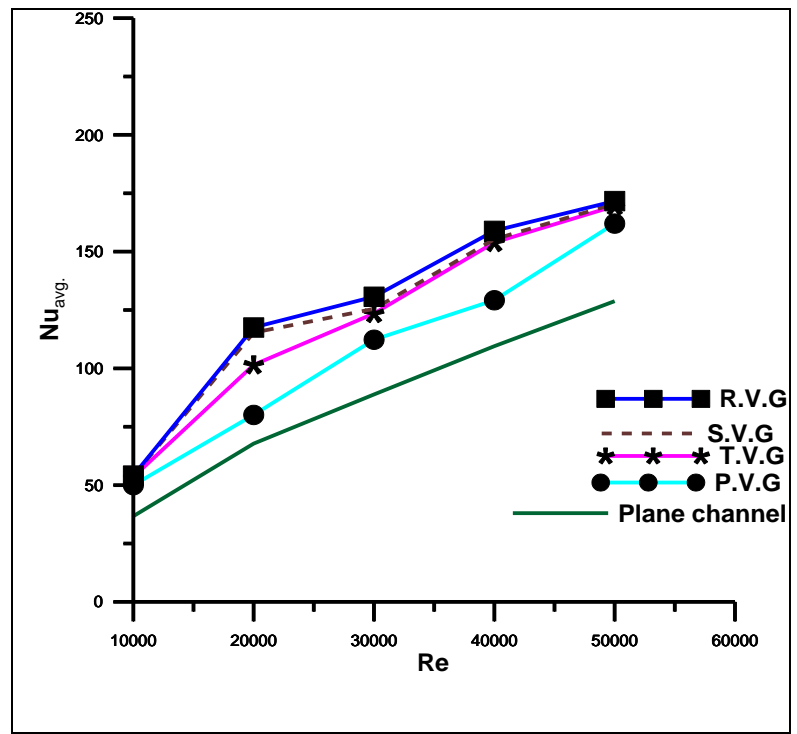

b. $A_{r}=0.0370$ 


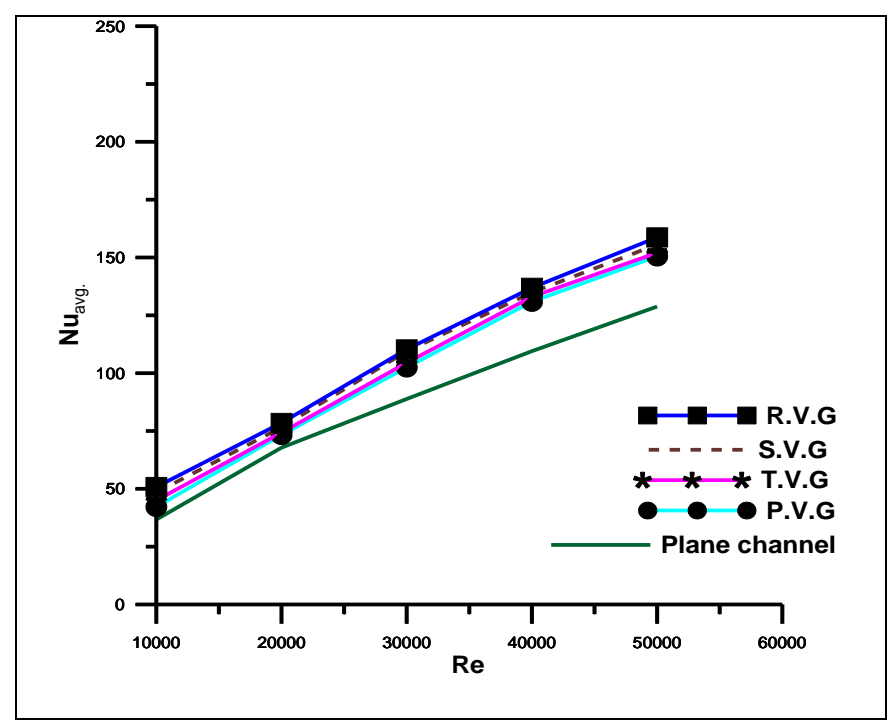

b. $\quad A_{r}=0.0231$

Fig(5)Variation of average Nusselt number with Reynolds number for different shapes of vortex generators for

$$
\beta=45^{\circ} \text { and } X_{r}=1.5 \text {. }
$$

Fig. $(6 \mathrm{a}, \mathrm{b}, \mathrm{c})$ shows the average skin friction coefficient distribution with Reynolds number for different shapes of vortex generators for $\beta=45^{\circ}$ and $\mathrm{X}_{\mathrm{r}}=1.5$. Generally, it can be seen that the average skin friction coefficient decreases with increasing Reynolds number. The friction factor enduced by using vortex generators is observed to be higher than that of the plane channel for all studied vortex generators shapes. This

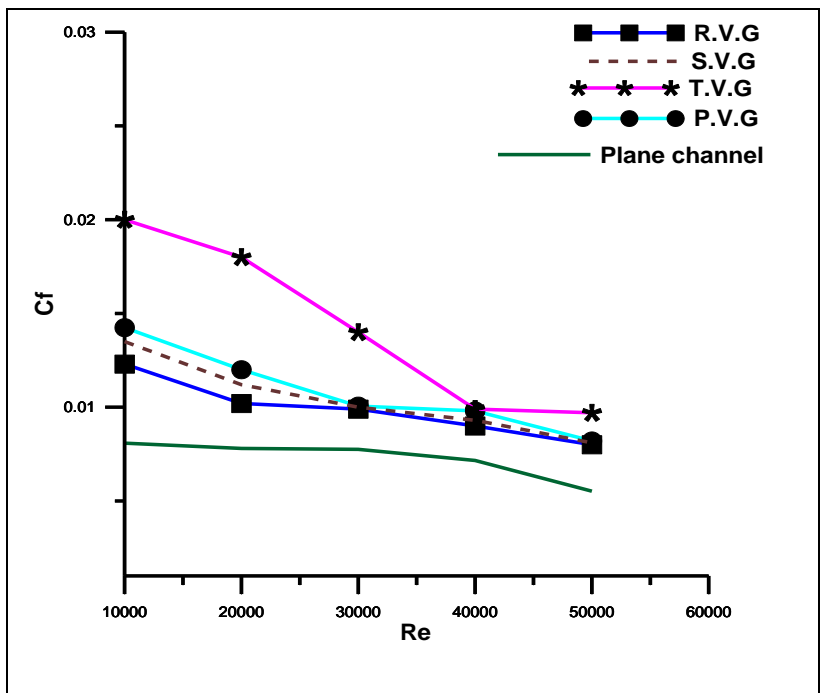

a. $\quad \mathbf{A}_{\mathrm{r}}=\mathbf{0 . 0 7 4 0}$ attributed to the suppression of the viscous sub-layer. This trend is increased as vortex generators area ratio increases. The increased drag is always associated with extra pressure loss. When the area ratio increases ,the strength of longitudinal vortices are increases result in a reverse flow leading to noticeable increase in friction factor as compared with plane channel.

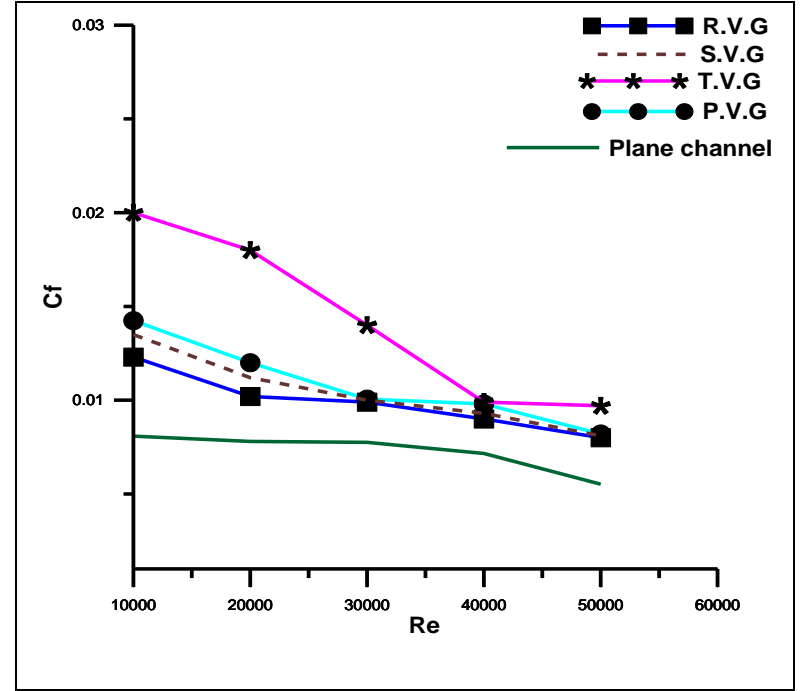

b. $A_{\mathbf{r}}=\mathbf{0 . 0 3 7 0}$ 
b.

c.

d.

e.

f.

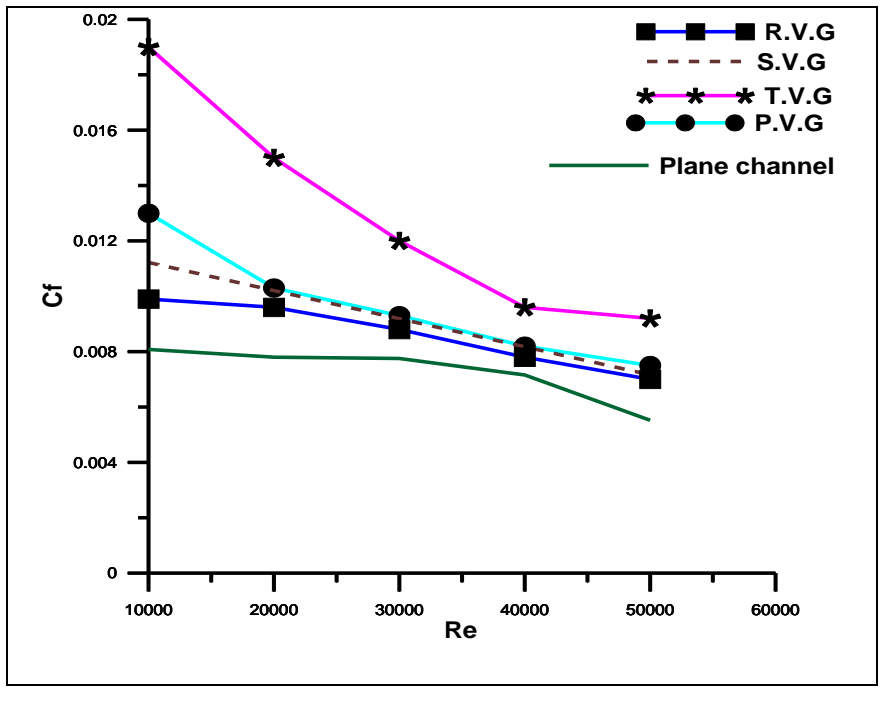

g.

h.

i. $\quad A_{r}=0.0231$

Fig(6)Variation of average skin friction factor with Reynolds number for different shapes of vortex generators for $\beta=45^{\circ}$ and $X_{r}=1.5$

Fig.(7 a, b, c) shows the variation of thermal enhancement ratio $\left(\mathrm{Nu}_{\text {with }} / \mathrm{Nu}_{\text {without }}\right)$ with Reynolds number for different shapes and sizes of vortex generators. It can be seen that the thermal enhancement ratio significantly increases with presence of vortex generators as compared with plane channel. This increase is noticed for any specified Reynolds number. For each vortex generator, it decreases as Reynolds number increases . The introduction of VGs generates the longitudinal vortices and secondary flow, which breaks the boundary layer development. The boundary layer is thinner and the heat transfer is enhanced. The disturbing and mixing of the flow results in dramatic changes in the flow structure and consequently affecting the recirculation zone and separation point. The higher area ratio of the winglet vortex generators greats more disturbance of the boundary layer and provides a better air flow mixing. Hence, the heat transfer is enhanced. The heat transfer enhancement from the rectangular vortex generator was significant more than those of other shapes vortex generators. The optimum increase is formed at an angle of $\operatorname{attack}\left(\beta=45^{\circ}\right)$. The thermal enhancement ratio varied from 1.5 to 2.4 with Re increasing. 


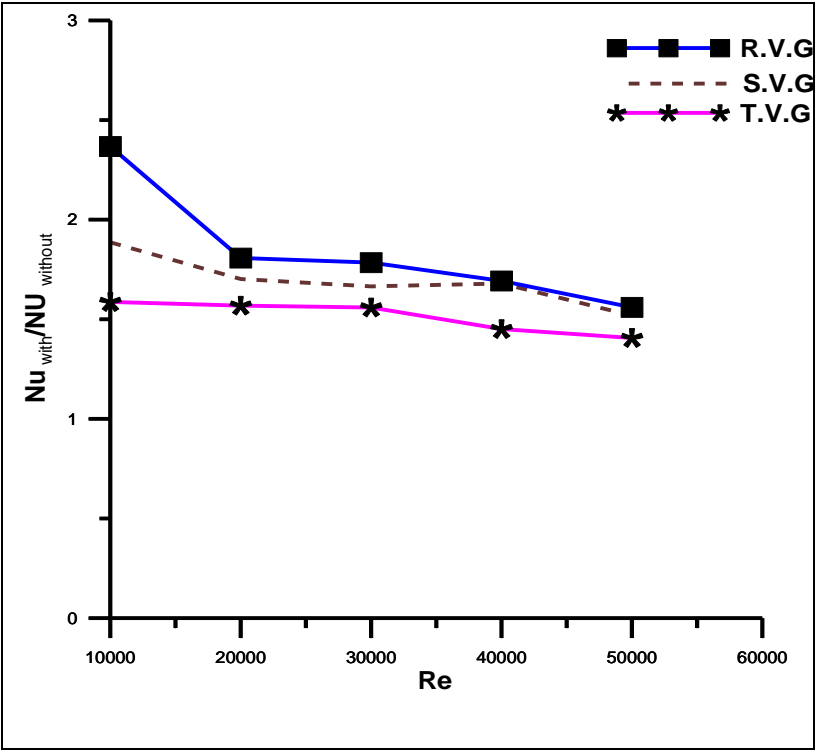

a. $A_{r}=0.0740$

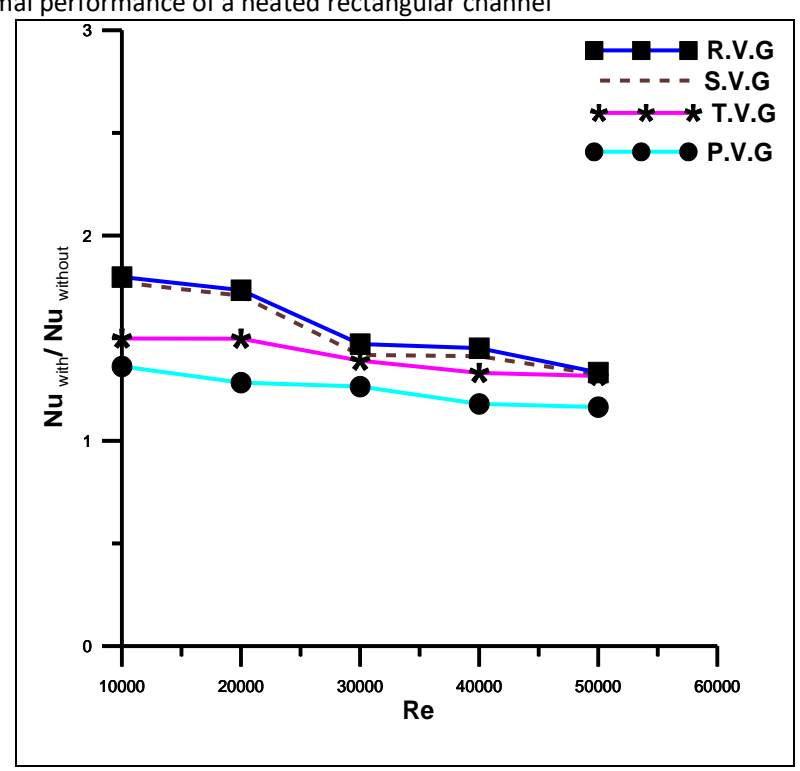

b. $A_{r}=0.0370$

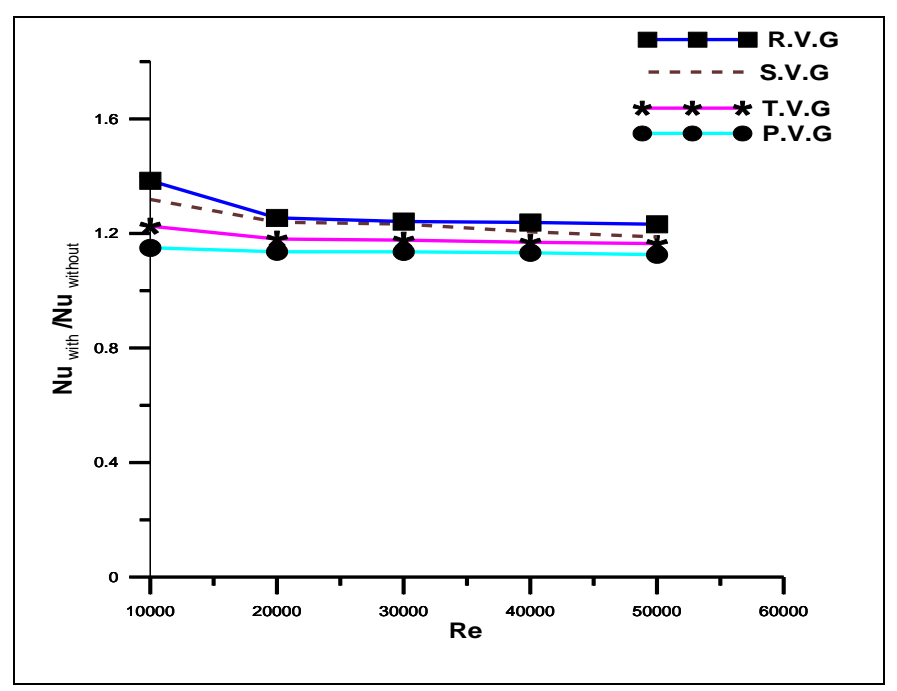

b.

c.

d.

e.

f. $\quad A_{r}=0.0231$

Fig(7)Variation of The Nusselt number ratio $\mathrm{N}_{\text {with }} / \mathrm{N}_{\text {without }}$ (enhancement ratio)with Reynolds number for different shapes of vortex generators for $\beta=45^{\circ}$ and $X_{r}=1.5$

Fig.(8) shows the overall efficiency versus Reynolds numbers with different shapes and size of winglet vortex generators. It can be seen that the overall efficiency $(\eta)$ are above unity for all the vortex generators. The enhancement factor tended to decrease with the rise in the Reynolds number values for all vortex generators. It is worth noting that the overall efficiency $(\eta)$ of the R.V.G shape were higher than of those other shapes for all Reynolds number values. In addition, the minimum overall efficiency is noticed at the parabolic vortex generators. This indicated that the use of R.V.G leads to the advantage over that of P.V.G. where the maximum overall efficiency $(\eta)$ is about 1.88 at $X_{r}=1.5$ and $\beta=45^{\circ}$. 


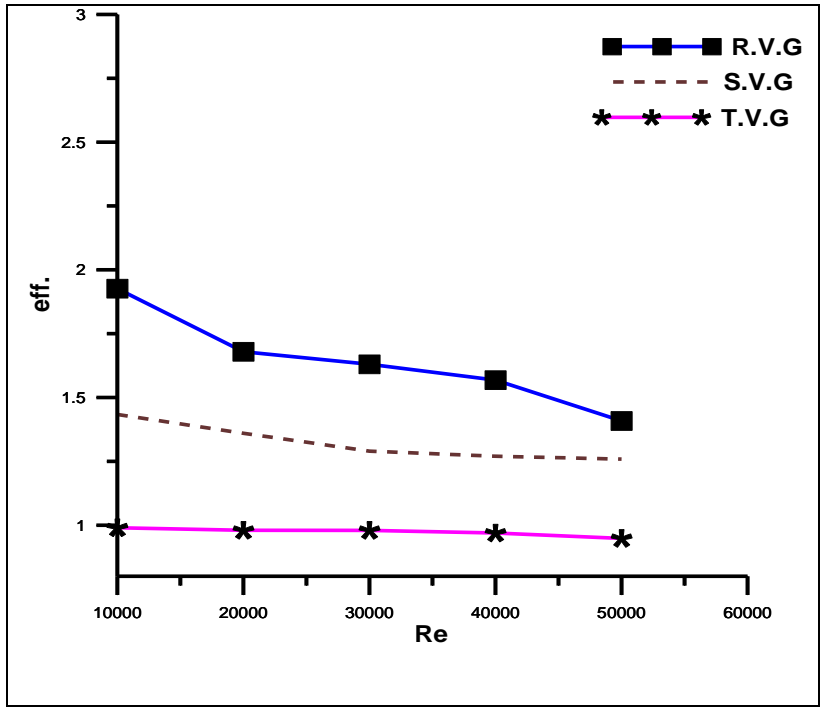

a. $A_{r}=0.0740$

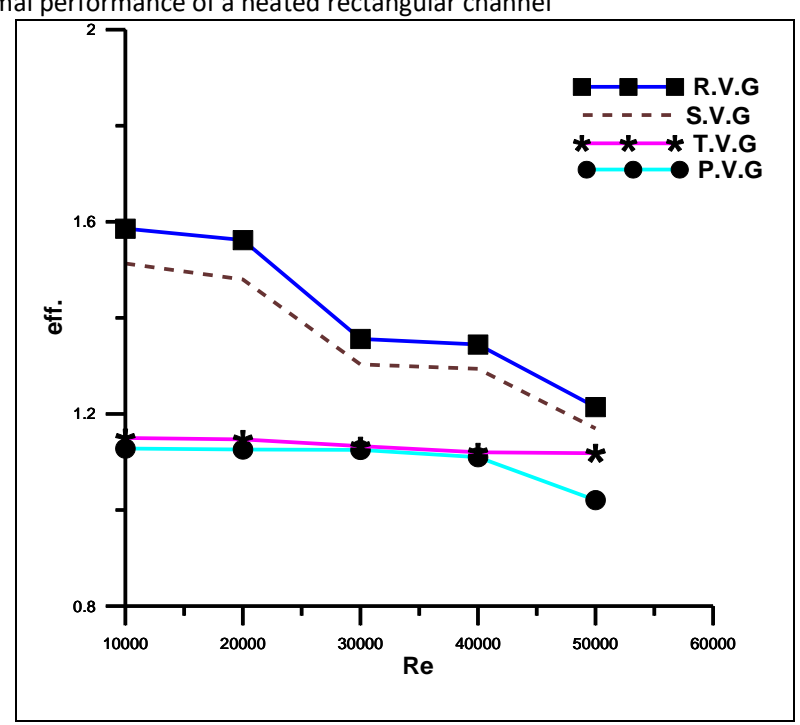

b. $A_{r}=0.0370$

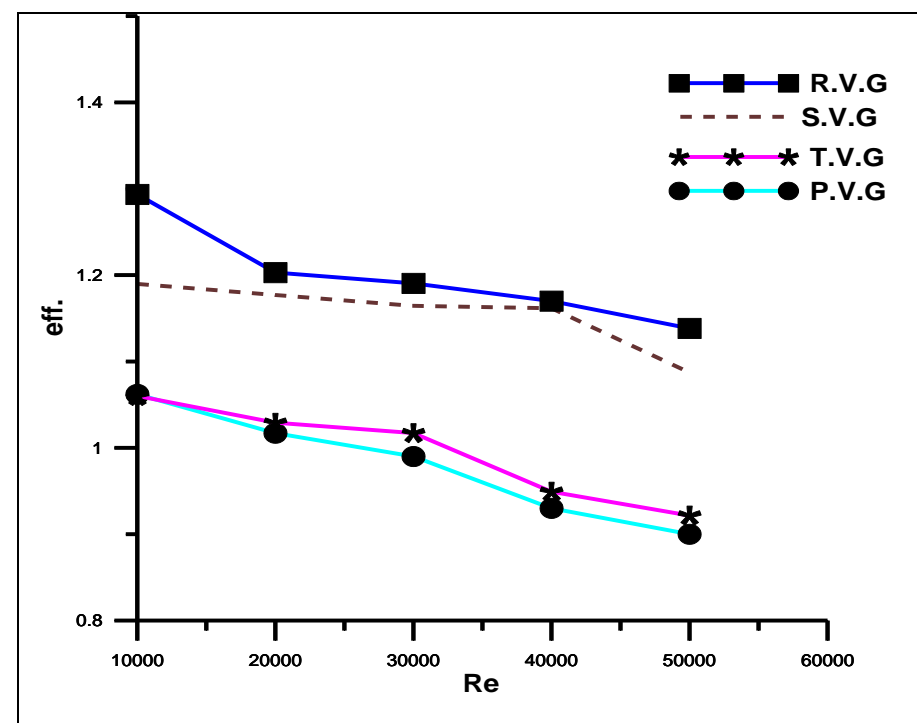

c. $A_{\mathbf{r}}=\mathbf{0 . 0 2 3 1}$

Fig(8)Variation of the overall efficiency with Reynolds number for different shapes of vortex generators for $\beta=45^{\circ}$

$$
\text { and } \mathrm{X}_{\mathrm{r}}=1.5
$$

Fig. (9) shows the comparison between the experimental and numerical results of the plane channel. It can be illustrates that the numerical results agree well with the experimental results, with the mean deviation being about $11 \%$. The agreement between the numerical and experimental results prove that the model and methods used in the present study are feasible and the numerical results are reliable. 


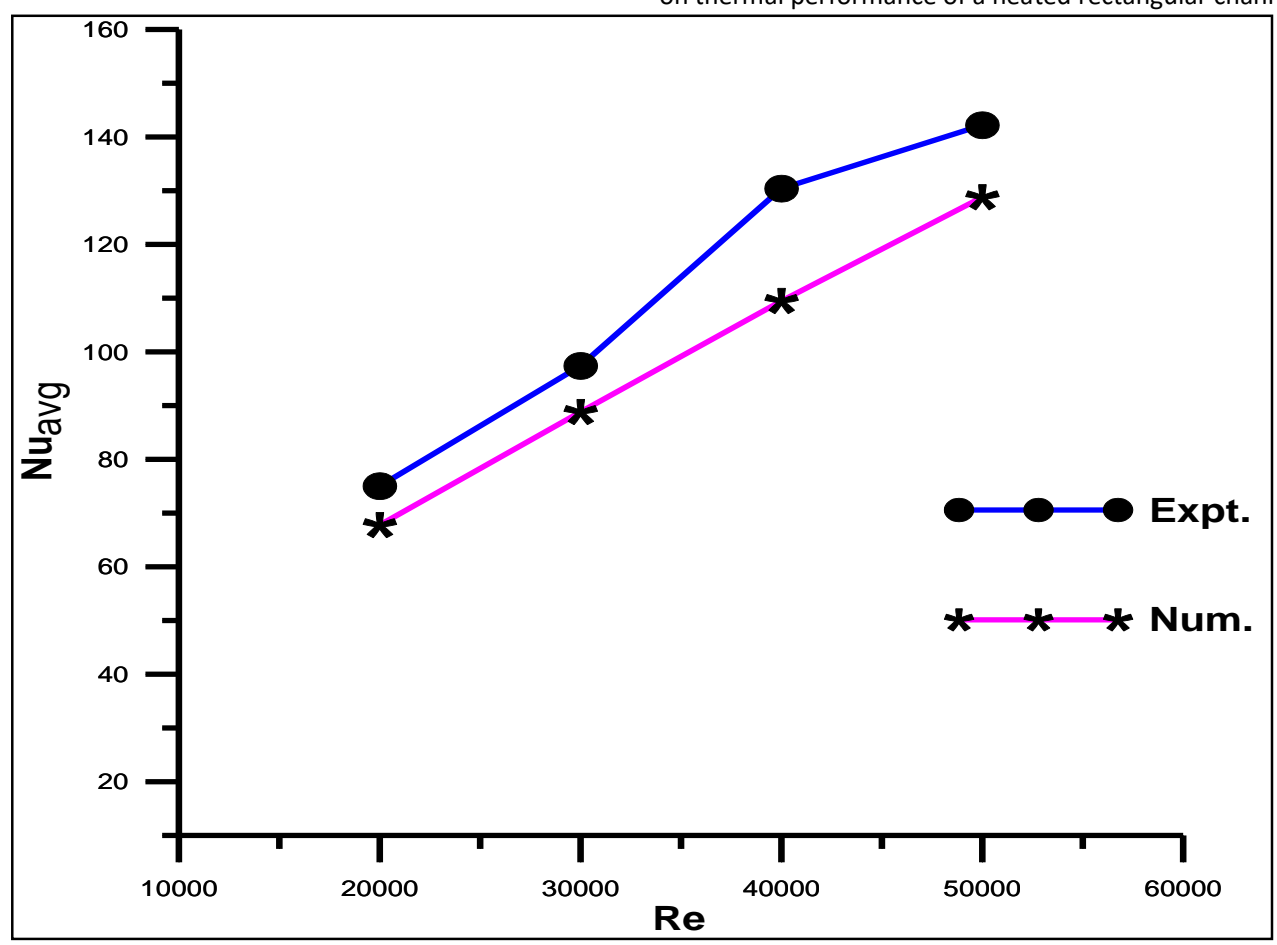

Fig. (9) The comparison between the experimental and numerical results of the channel.

Fig.(10) shows the comparison between numerical and experimental results of average Nusselt number against Reynolds number for $\beta=45^{\circ}$ and $\mathrm{A}_{\mathrm{r}}=0.0370$ and $\mathrm{X}_{\mathrm{r}}=3$. The deviation percentage for T.V.G was found to be about (7\%) between the

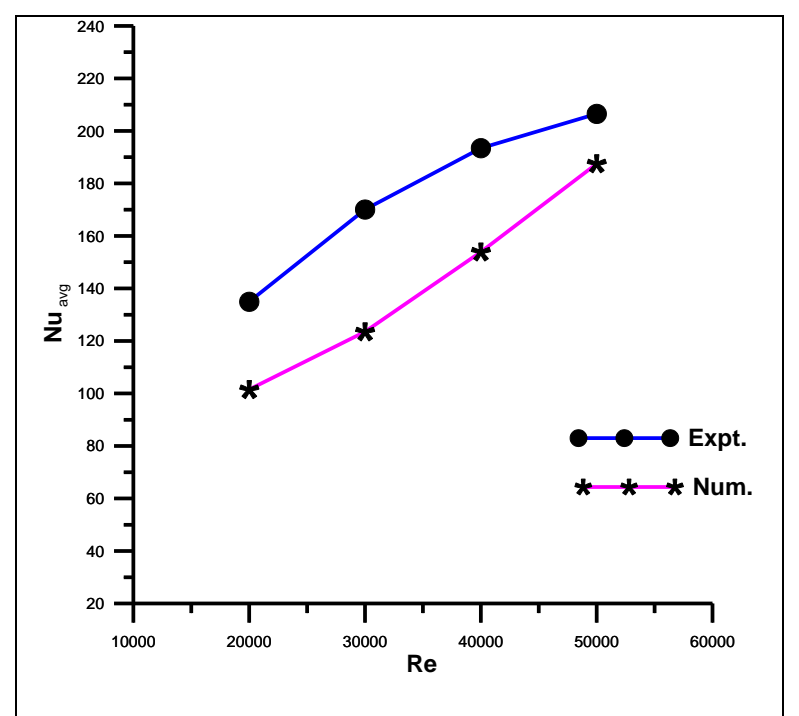

a-T.V.G experimental and numerical result. while the R.V.G was about $(4.7 \%),(4.4 \%)$ for S.V.G and P.V.G about (4.9\%). These deviation values verifies that a good approach is followed for experimental and numerical work. 


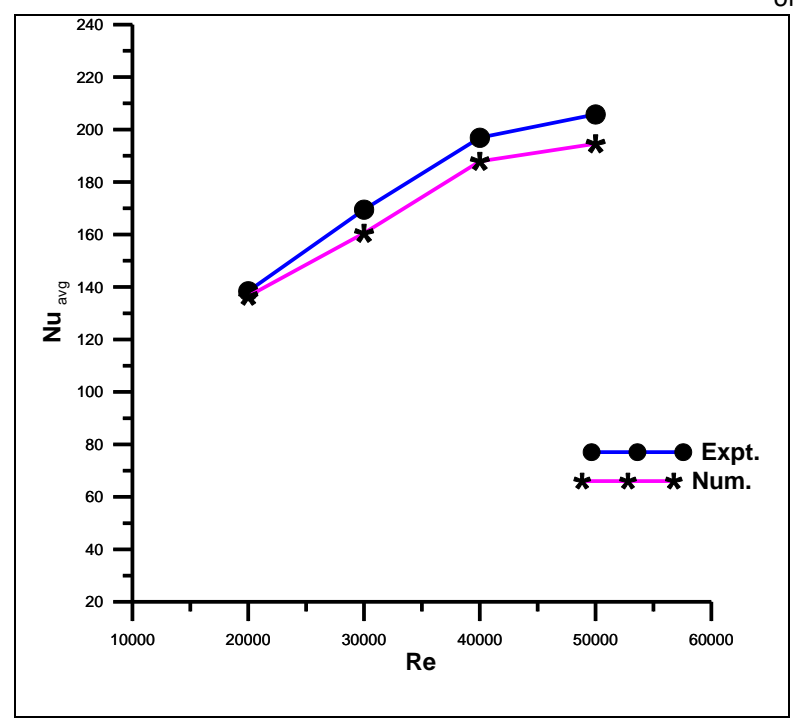

c-S.V.G

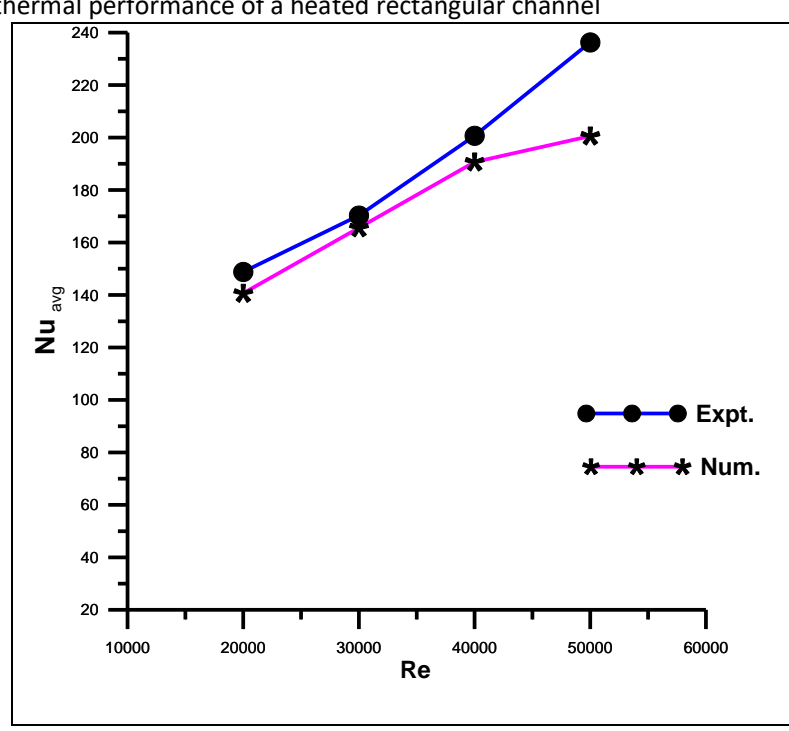

d-R.V.G

Fig.(10) Comparison between the average Nusselt number experimentally and numerically results for many value of Reynolds number for $\beta=45^{\circ}$ and $A_{r}=0.0370, X_{r}=3$.

The results of experimental work are governed by empirical equations for four shapes of vortex generators which it arranged in bottom of the rectangular channel.

$N u=0.957 \operatorname{Pr}^{0.4} \operatorname{Re}^{0.4966}\left(\frac{\pi}{2}+\beta\right)^{0.387726} X r^{0.1467}$

$N u=1.2457 \operatorname{Pr}^{0.4} R e^{0.4044}\left(\frac{\pi}{2}+\beta\right)^{0.4119} X r^{0.135}$

$N u=1.2928 \operatorname{Pr}^{0.4} \operatorname{Re}^{0.436}\left(\frac{\pi}{2}+\beta\right)^{0.42119} X r^{0.1469}$

$N u=0.944 \operatorname{Pr}^{0.4} \operatorname{Re}^{0.5}\left(\frac{\pi}{2}+\beta\right)^{0.36} X r^{0.11933}$

\subsection{Contour}

The velocity contour for a specified zone $\left(\mathrm{Zr}=1.5, \mathrm{X}_{\mathrm{r}}=12\right.$ and $\left.\mathrm{Y}_{\mathrm{r}}=1 / 6\right)$ of the plane channel with triangular vortex generators at $\beta=30^{\circ}$ and $\mathrm{Re}=30000$ is depicted in Fig.(11) . As the figure shows, the main flow strikes each pair of vortex generators causing the flow separation and forming two strong longitudinal vortices behind the winglet vortex generators. The gradient of colors verifies the values of axial velocity where it has a maximum value at the tip of each vortex generator. The strength
The equations shows an empirical equation for the channel with vortex generators.

For R.V.G

For S.V.G

For T.V.G

For P.V.G

of the two resulting longitudinal vortices is responsible for disturbance of thermal boundary layer where the hot and cold fluid is mixed and the heat transfer is enhanced.

The velocity contour for a specified plane $\left(\mathrm{Zr}=1.5, \mathrm{X}_{\mathrm{r}}=12\right.$ and $\left.\mathrm{Y}_{\mathrm{r}}=1 / 6\right)$ of the channel with rectangular vortex generators is depicted in Fig.(12). From this figure, it can be noted that the maximum velocity is located in the outer edge of the set vortex and the minimum velocity appears near the tip of each vortex. This figure shows that the 
vortices become greater and the turbulence intensity as compared with triangular. After the vortex generators region, the strong transverse secondary flow generated from the longitudinal vortices effectively reduced the size of the wake zone.
Effect of winglet vortex generators configuration on thermal performance of a heated rectangular channel

Meanwhile, the fluid with high momentum is redirected to the channel surface by the longitudinal vortices, which, in turn, effectively delays the separation of boundary layer on the channel.

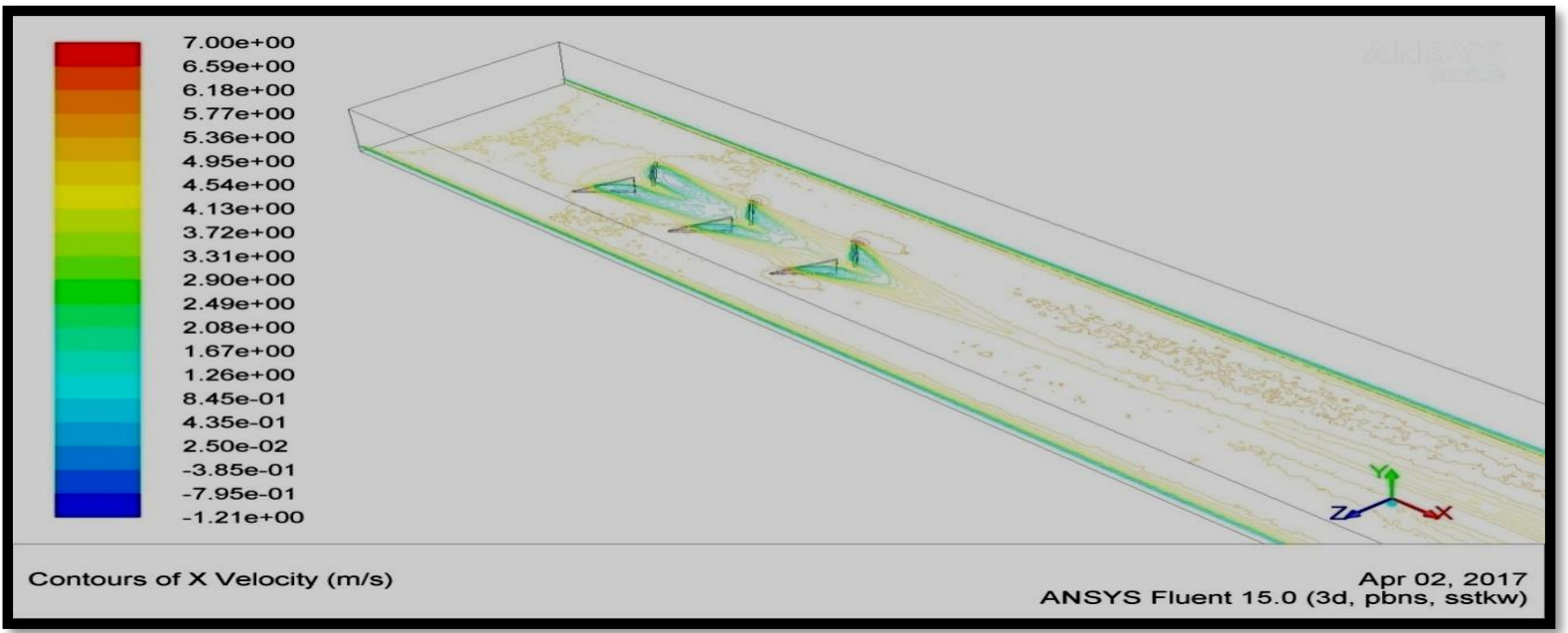

Fig.(11) Velocity contour of $\operatorname{Re}=30000$ and $\mathrm{Zr}=1.5$ at $\mathrm{X}_{\mathrm{r}}=12, \mathrm{Yr}=1 / 6$ for triangular shape $\beta=30^{\circ}$

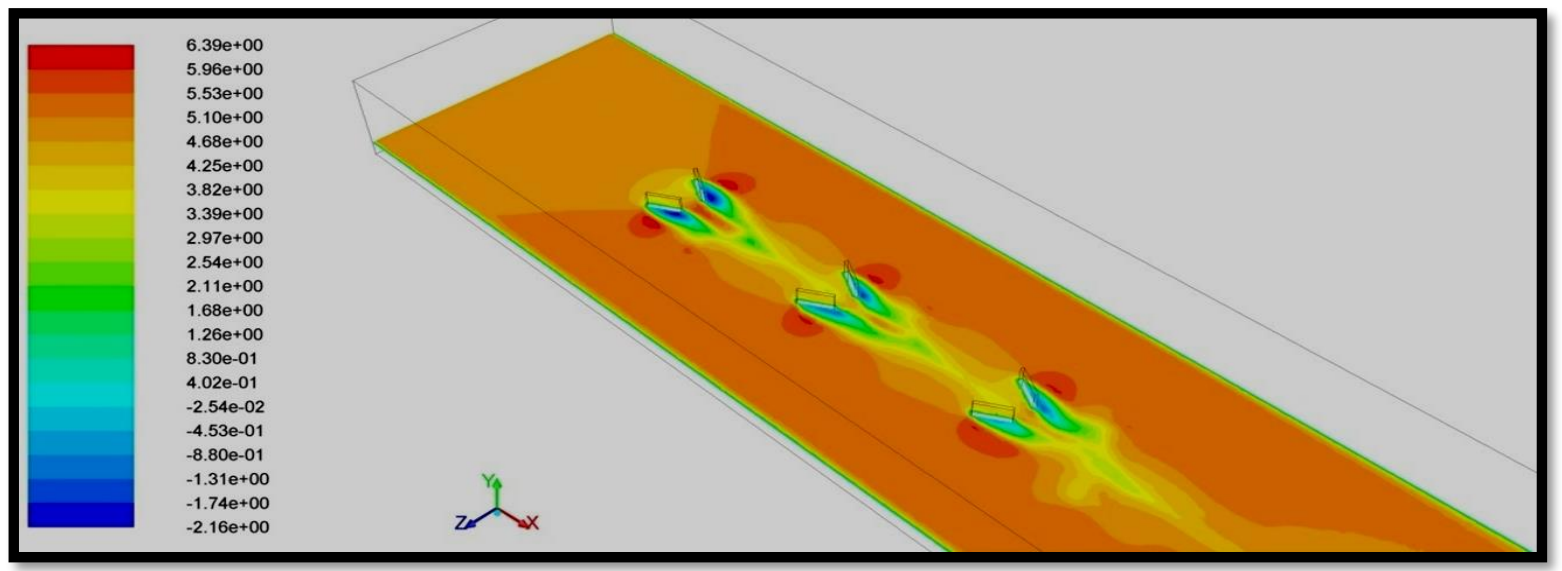

Fig.(12) Velocity contour of $\operatorname{Re}=30000$ and $\mathrm{Zr}=1.5$ at $\mathrm{X}_{\mathrm{r}}=12, \mathrm{Yr}=1 / 6$ for rectangular shape $\beta=30^{\circ}$.

\section{Conclusions}

The potential using of winglet vortex generators array with different shapes, and arrangements in a three dimensional plane channel turbulent flow been conducted experimentally and numerically .The conclusions obtained from this investigation have been listed as follows:

1-It was found that the strength of the two longitudinal vortices induced by rectangular winglet vortex generators is higher as compared with other tested shapes.
2-Utilizing rectangular winglet vortex generators array indicated the optimum heat transfer enhancement with modest pressure drop.

3- The stream wise distance between winglet vortex generators has more effect on heat transfer and pressure drop as compared with span wise distance.

4-The stream wise distance $\left(X_{r}\right)$ represents the optimum distance for enhancing the heat transfer . 
Effect of winglet vortex generators configuration on thermal performance of a heated rectangular channel $165 \%)$ and (108\%-121\%)respectively as compared with plane channel.

9-The penalty increase in friction factor ratio for rectangular, triangular, semicircle and parabolic winglet vortex generators by $(140 \%-161 \%),(198 \%$ $226 \%),(158-177 \%)$ and $(181 \%-220 \%)$ respectively as compared with plane channel

10- The area ratio $\left(\mathrm{A}_{\mathrm{r}}\right)$ as 0.0073 achieved the best average Nusselt number ,but the highest the friction factor.

11- The increasing stream wise distance $\left(\mathrm{X}_{\mathrm{r}}\right)$ leads to increase of heat transfer, where as $X_{r}=3$ have better than the other distances.

\section{Nomenclature}

\begin{tabular}{|c|c|c|}
\hline Symbol & Definition & $\begin{array}{c}S I \\
\text { Uni } \\
\text { ts }\end{array}$ \\
\hline $\mathrm{Nu}$ & Nusselt number & - \\
\hline $\mathrm{Nu}_{\text {avg }}$ & Average Nusselt number & - \\
\hline $\begin{array}{l}\mathrm{Nu}_{\text {with }} / \mathrm{Nu}_{\text {wit }} \\
\text { hout }\end{array}$ & $\begin{array}{l}\text { Thermal enhancement } \\
\text { ratio }\end{array}$ & \\
\hline $\mathrm{P}$ & Pressure & $\mathrm{Pa}$ \\
\hline $\mathrm{P}_{\mathrm{D}}$ & The dynamic pressure & $\mathrm{Pa}$ \\
\hline q & Heat Flux & $\begin{array}{l}\mathrm{W} / \\
\mathrm{m}^{2}\end{array}$ \\
\hline $\operatorname{Re}$ & Reynolds number & - \\
\hline $\mathrm{T}$ & Temperature & $\mathrm{K}$ \\
\hline $\mathrm{Tb}$ & Bulk temperature & $\mathrm{K}^{\circ}$ \\
\hline $\mathrm{T}_{\mathrm{w}}$ & Wall temperature & $\mathrm{K}^{\circ}$ \\
\hline $\mathrm{u}$ & Velocity in $\mathrm{x}$-direction & $\mathrm{m} / \mathrm{s}$ \\
\hline
\end{tabular}




\begin{tabular}{|c|l|c|}
\hline Symbol & \multicolumn{1}{|c|}{ Definition } & $\begin{array}{c}\text { SI } \\
\text { Uni } \\
\boldsymbol{t}\end{array}$ \\
\hline $\mathrm{U}$ & Bulk inlet velocity & $\mathrm{m} / \mathrm{s}$ \\
\hline V & Velocity in y-direction & $\mathrm{m} / \mathrm{s}$ \\
\hline W & $\begin{array}{l}\text { Channel width } \\
\text { channel inlet to the first } \\
\text { pair of vortex generators }\end{array}$ & $\mathrm{m}$ \\
\hline W & $\begin{array}{l}\text { Velocity in z-direction } \\
\text { The distance from the }\end{array}$ & $\mathrm{m} / \mathrm{s}$ \\
\hline
\end{tabular}

\begin{tabular}{|l|l|c|}
\hline Symbol & \multicolumn{1}{|c|}{ Definition } & $\begin{array}{c}\text { SI } \\
\text { Uni } \\
\text { ts }\end{array}$ \\
\hline $\mathrm{X}_{\mathrm{r}}$ & Streamwise distance $=\frac{p}{H}$ & \\
\hline $\mathrm{y}$ & Transverse coordinate & $\mathrm{m}$ \\
\hline $\mathrm{z}$ & Span wise coordinate & $\mathrm{m}$ \\
\hline $\mathrm{Z}_{\mathrm{r}}$ & Span wise distance $=\frac{s}{H}$ & \\
\hline
\end{tabular}

Greek Symbols

\begin{tabular}{|c|l|l|}
\hline Symbol & \multicolumn{1}{|c|}{ Definition } & \multicolumn{1}{|c|}{ Unite } \\
\hline$\beta$ & Angle of attack & \\
\hline $\boldsymbol{V}$ & Kinematics viscosity $(\mu / \rho)$ & $\mathrm{m}^{2} / \mathrm{s}$ \\
\hline $\boldsymbol{\Gamma}$ & Diffusion coefficient & - \\
\hline$\phi$ & Generalized variable & - \\
\hline$\tau$ & Shear stress & $\mathrm{N} / \mathrm{m}^{2}$ \\
\hline
\end{tabular}

\begin{tabular}{||c|l|l|}
\hline$\tau_{\mathrm{w}}$ & Wall shear stress & $\mathrm{N} / \mathrm{m}^{2}$ \\
\hline$\theta$ & Dimensionless Temperature & - \\
\hline$\mu$ & Dynamic Viscosity & $\mathrm{N} \mathrm{s} / \mathrm{m}^{2}$ \\
\hline$\rho$ & Density & $\mathrm{kg} / \mathrm{m}^{3}$ \\
\hline$\eta$ & Overall efficiency & \\
\hline
\end{tabular}

configuration for fin-tube heat exchangers. Number

Heat Transfer Part

A 2003;43:201e19.

[4] M.C. Gentry, A.M. Jacobi, Heat transfer enhancement by delta-wing vortex generators on a flat plate: vortex interactions with the boundary layer, Exp. Therm. Fluid Sci. 14 (3) (1997) 231-242. [5] M.C. Gentry, A.M. Jacobi, Heat transfer enhancement by delta-wing-generated tip vortices in flat-plate and developing channel flows, ASME J. Heat Transfer 124 (6) (2002) 1158-1168.

[6] T.M. Liou, C.C. Chen, T.W. Tsai, Heat transfer and fluid flow in a square duct with 12 different

\section{Reference}

[1] S. Ferrouillat, P. Tochon, C. Garnier, H. Peerhossaini, Intensification of heat transfer and mixing in multifunctional heat exchangers by artificially generated stream wise vorticity, Appl. Therm. Eng. 26 (16) (2006) 1820-1829.

[2] M. Fiebig, P. Kallweit, N.K. Mitra, St. Tiggelbeck, Heat transfer enhancement and drag by longitudinal vortex generators in channel flow, Exp. Therm. Fluid Sci. 4 (1) (1991) 103e114.

[3] Jain A, Biswas G, Maurya D. Winglet-type vortex generators with common flow- up 
Effect of winglet vortex generators configuration on thermal performance of a heated rectangular channel shaped vortex generators, ASME J. Heat Transfer 122 (2) (2000) 327-335.

[7] Du XZ, Feng LL, Li L, Yang L, Yang LY. Heat transfer enhancement of wavy finned flat tube by punched longitudinal vortex generators. Int J Heat Mass Transfer2014;75:368-80.

[8] C. Habchi, S. Russeil, D. Bougeard, J.L. Harion, T. Lemen and, D.D. Valle,

H. Peerhossaini, Enhancing heat transfer in vortex generator-type multifunctional heat exchangers, Appl. Therm. Eng. 38 (2012) 14-25.

[9] J.M. Wu, W.Q. Tao, Numerical study on laminar convection heat transfer in a rectangular channel with longitudinal vortex generator. Part A: verification of field synergy principle, Int. J. Heat Mass Transf. 51 (2008) 1179-1191.

[10] G. Zhou, Q. Ye, Experimental investigations of thermal and flow characteristics of curved trapezoidal winglet type vortex generators, Appl. Therm. Eng. 37 (2012) 241-248.

[11] Q. Wang, Q. Chen, L. Wang, M. Zeng, Y. Huang, Z. Xiao, Experimental study of heat transfer enhancement in narrow rectangular channel with longitudinal vortex generators, Nuclear Engineering Design 237 (2007) 686-693.

2321-3264. 